\title{
Afetividade como prática metodológica na educação infantil: Uma revisão narrativa
}

\author{
Affectivity as a methodological practice in children's education: A narrative review
}

Afectividad como práctica metodológica en la educación infantil: Una revisión narrativa

Kaio Germano Sousa da Silva ORCID: https://orcid.org/0000-0003-4236-6230 Centro Universitário de Ciências e Tecnologia do Maranhão, Brasil

E-mail: kaiogsds@hotmail.com

Nilzete Lima Costa dos Santos ORCID: https://orcid.org/0000-0003-0589-4480

Universidade Estadual do Maranhão, Brasil E-mail: nutrialuno@hotmail.com

Francisca Thawanny de Souza Silva ORCID: https://orcid.org/0000-0003-2880-0985 Centro Universitário de Ciências e Tecnologia do Maranhão, Brasil

E-mail: kaiogermano123890@gmail.com

Solange Gonçalves Nunes de Sousa ORCID: https://orcid.org/0000-0003-4327-9323

Universidade Estadual do Maranhão, Brasil E-mail: solange.nunes_@hotmail.com

Cristiane Dutra do Nascimento ORCID: https://orcid.org/0000-0002-8563-6547 Centro Universitário Leonardo da Vinci, Brasil E-mail: cdncristie.tjls@hotmail.com

Conceição de Maria Machado Costa Primo ORCID: https://orcid.org/0000-0002-0837-2314 Centro Universitário Leonardo da Vinci, Brasil E-mail: mara.con6ao@hotmail.com

Saleia Soares Leitão Silva

ORCID: https://orcid.org/0000-0001-8627-3680 Universidade Federal do Piauí, Brasil E-mail: saleiasoares@hotmail.com

Ranna Johara de Cunha Bacelar de Oliveira Sousa ORCID: https://orcid.org/0000-0001-9373-2304 Centro Universitário Leonardo da Vinci, Brasil E-mail: rannajoharab79@gmail.com Jânio Oliveira Lima ORCID: https://orcid.org/0000-0002-9489-6607

Universidade Estadual do Maranhão, Brasil E-mail: janio_jol@hotmail.com

Marta Alves de Oliveira Silva ORCID: https://orcid.org/0000-0001-8309-8610 Faculdade do Vale do Itapecuru, Brasil

E-mail: martaalvesoliveira@ hotmail.com

Marise Silva Lima de Mesquita ORCID: https://orcid.org/0000-0002-5666-2658 Faculdade do Vale do Itapecuru, Brasil E-mail: mariseslm@hotmail.com

Apollo Habacuque dos Santos Cunha ORCID: https://orcid.org/0000-0001-7791-3834 Faculdade São Marcos, Brasil E-mail: apollo199521@gmail.com

Simone Neves Queiroz de Freitas ORCID: https://orcid.org/0000-0002-7295-4511 Universidade Federal do Piauí, Brasil E-mail: simonenqfreitas@hotmail.com

Christyanne de Jesus Pereira Oliveira ORCID: https://orcid.org/0000-0003-4846-6865 Universidade Anhanguera, Brasi

E-mail: christy-oliveira03@hotmail.com Karine Costa Melo ORCID: https://orcid.org/0000-0001-8253-859X 


\title{
Resumo
}

A afetividade promove transformações na educação, permitindo estimular o prazer durante o aprendizado, favorecendo a criança a uma melhor adaptação ao meio, e torna-se necessário sua inserção como prática pedagógica. O objetivo desse estudo foi investigar a importância da afetividade na educação infantil. Trata-se de uma revisão bibliográfica de cunho narrativa, descritiva e exploratória. A partir da temática "A afetividade como prática metodológica na educação infantil: uma revisão narrativa", formulou a seguinte questão norteadora: Qual a importância da afetividade como prática metodológica no ensino de crianças? E foram consultados bases dados online de pesquisa tais como ScieLO, ERIC, Google Acadêmico. Ao todo dezenove artigos (19) foram selecionados, conforme os critérios de inclusão e exclusão. Os estudos abordavam sobre os conceitos de afetividade e sua relação com o ensino, a afetividade no contexto familiar, o papel do docente na utilização da afetividade em sala de aula, e a importância da afetividade no ensino da educação infantil para o desenvolvimento e aprendizado das crianças. A afetividade deve ser vista como uma abordagem prática no ensino das crianças como estratégia positiva no processo de aprendizagem, estratégias estas que podem ser desenvolvidas pelo professor no ambiente escolar, e também no âmbito familiar, pois o vínculo entre o aluno e sua família propiciam benefícios quanto a sociabilidade e aprendizagem.

Palavras-chave: Afetividade; Ensino; Aprendizagem; Educação infantil.

\begin{abstract}
Affection promotes transformations in education, allowing to stimulate pleasure during learning, favoring the child to better adapt to the environment, and its insertion as a pedagogical practice becomes necessary. The aim of this study was to investigate the importance of affectivity in early childhood education. This is a narrative, descriptive and exploratory bibliographic review. Based on the theme "Affectivity as a methodological practice in early childhood education: a narrative review", he formulated the following guiding question: What is the importance of affectivity as a methodological practice in teaching children? And online research databases such as ScieLO, ERIC, Google Scholar were consulted. In all, nineteen articles (19) were selected, according to the inclusion and exclusion criteria. The studies addressed the concepts of affectivity and its relationship with teaching, affectivity in the family context, the role of the teacher in the use of affectivity in the classroom, and the importance of affectivity in the teaching of early childhood education for the development and learning of children. kids. Affection must be seen as a practical approach in teaching children as a positive strategy in the learning process, strategies that can be developed by the teacher in the school environment, and also in the family context, as the bond between the student and his family provides benefits as for sociability and learning.
\end{abstract}

Keywords: Affectivity; Teaching; Learning; Child education.

\section{Resumen}

El afecto promueve transformaciones en la educación, permitiendo estimular el placer durante el aprendizaje, favoreciendo que el niño se adapte mejor al entorno, y se hace necesaria su inserción como práctica pedagógica. El objetivo de este estudio fue investigar la importancia de la afectividad en la educación infantil. Es una revisión bibliográfica narrativa, descriptiva y exploratoria. A partir del tema "La afectividad como práctica metodológica en la educación infantil: una revisión narrativa", formuló la siguiente pregunta orientadora: ¿Cuál es la importancia de la afectividad como práctica metodológica en la enseñanza a los niños? Y se consultaron bases de datos de investigación en línea como ScieLO, ERIC, Google Scholar. En total, se seleccionaron diecinueve artículos (19), de acuerdo con los criterios de inclusión y exclusión. Los estudios abordaron los conceptos de afectividad y su relación con la docencia, la afectividad en el contexto familiar, el papel del docente en el uso de la afectividad en el aula y la importancia de la afectividad en la enseñanza de la educación infantil para el desarrollo y el aprendizaje. de los niños. El afecto debe ser visto como un enfoque práctico en la enseñanza de los niños como una estrategia positiva en el proceso de aprendizaje, estrategias que pueden ser desarrolladas por el docente en el ámbito escolar, y también en el contexto familiar, ya que el vínculo entre el alumno y su familia proporciona beneficios en cuanto a sociabilidad y aprendizaje.

Palabras clave: Afectividad; Enseñando; Aprendiendo; Educación infantil.

\section{Introdução}

A afetividade promove transformações na educação, permitindo estimular o prazer durante o aprendizado, favorecendo a criança a uma melhor adaptação ao meio, e torna-se necessário sua inserção como prática pedagógica, proporcionado benefícios tanto para os discentes e suas famílias, como para os docentes e toda a comunidade escolar (Leite, 2012). 
No âmbito da educação infantil a afetividade proporciona ações positivas no intuito de melhorar a qualidade de vida das crianças, o seu desempenho e desenvolvimento de suas habilidades no ambiente escolar, tais estratégias devem ser colocadas em prática levando em consideração uma avaliação individual de cada criança, compreendendo suas necessidades e dificuldades, a fim de obter melhores resultados durante o processo socioeducativo (Ornellas, 2009).

Nessa perspectiva, discutir a afetividade tanto no meio escolar como familiar é de grande contribuição para formulação de estratégias, permitindo compreender o comportamento dos discentes e como as relações sociais influenciam nas diferentes esferas da sua vida, e a família como protagonista no aprender e ensinar é fundamental para o progresso do aluno, e a ausência familiar nesse processo pode contribuir de forma negativa, colocando o professor em conflito e obrigando o mesmo, sozinho, a resolver futuros desafios e problemas que poderiam ser inexistentes na vida do aluno se a família participasse afetivamente (Almeida \& Mahoney, 2007).

Destaca-se que a afetividade no contexto educacional representa uma ferramenta metodológica para o ensinar e o educar dos alunos, possibilitando a formação e o estabelecimento dos vínculos afetivos saudáveis e harmônicas, que é necessário para a vida de todos os indivíduos desde o seu concebimento e posteriormente durante o decorrer da vida, seja na escola em relação ao ensino e aprendizagem ou outras esferas sociais.

Levando em consideração a temática, optou-se por uma revisão de literatura de cunho narrativa para o desenvolvimento do estudo, tendo como ponto de partida o seguinte questionamento: Qual a importância da afetividade como prática metodológica no ensino de crianças? E determinou-se como objetivo geral investigar a importância da afetividade na educação infantil no ensino das crianças, e especificamente descrever acerca da relação entre afetividade e o ensino; explanar sobre afetividade no contexto familiar; e destacar sobre o papel do docente e a afetividade na escola.

\section{Metodologia}

Trata-se de uma revisão bibliográfica de cunho narrativa, descritiva e exploratória. De acordo com Mendes, Silveira e Galvão (2008), a revisão bibliográfica é um dos métodos de revisão de literatura mais utilizados na prática baseada em evidências (PBE) que tem como finalidade identificar, através de pesquisas, se um tratamento ou meio diagnóstico é efetivo, avaliando a qualidade dos estudos e mecanismos para a execução na assistência. Envolve a definição de um problema, a busca e a avaliação crítica das evidências disponíveis, a implementação das evidências na prática e na avaliação dos resultados obtidos.

A pesquisa descritiva possibilita aos pesquisadores uma observação e interpretação ampla e individual dos dados conforme o interesse do estudo, permitindo avaliar e detalhar os melhores desfechos para a pesquisa (Lakatos \& Marconi, 2010). Enquanto que a pesquisa exploratória permite o pesquisador a compreender e aprimorar o conhecimento sobre seu objeto de estudo, possibilitando que seus resultados possam instigar a novas produções cientificas e novas abordagens (Carvalho, Duarte, Menezes, \& Souza, 2019).

A partir da temática "A afetividade como prática metodológica na educação infantil no ensino de crianças”, formulou a seguinte questão norteadora: Qual a importância da afetividade como prática metodológica no ensino de crianças? E foram consultados bases dados online de pesquisa tais como SCIELO, ERIC, Google Acadêmico. Na qual foram utilizados os seguintes descritores e palavras-chaves: Afetividade, ensino, aprendizagem, e educação infantil.

Tendo como critérios de inclusão artigos em sua totalidade, livros, capítulos de livros, teses e monografias, com o recorte temporal trabalhos produzidos na última década (2011-2021), incluindo ainda, obras clássicas (que caracterizam os artigos científicos, que regem os princípios teóricos do estudo). Priorizando publicações nacionais que contemplassem a 
temática do estudo. Foram excluídos resumos, manuais técnicos, artigos incompletos e estudos que estivessem fora do recorte temporal estabelecido.

\section{Resultados e Discussão}

A busca resultou ao todo em quarenta (40) artigos, em seguida foram aplicados os critérios de inclusão e exclusão resultando em trinta (30) artigos pré-selecionados, após a leitura dos títulos e se estes comtemplavam a temática obteve-se vinte e oito (28) artigos. Em seguida foi feita a leitura na integra dos estudos, resultando em dezenove (19) artigos selecionados. Os estudos selecionados foram interpretados, sintetizados e compilados a partir do eixo central da pesquisa e organizados conforme os objetivos definidos na pesquisa e respeitando a autoria dos estudos.

\section{A relação entre o ensino e a afetividade}

A afetividade pode ser definida como um conjunto de fenômenos psíquicos manifestados sob forma de emoções ou sentimentos e acompanhados da impressão de prazer ou dor, alegria ou tristeza. A afetividade é muito importante para nós, pois nos torna seres conscientes de nossa realidade mais profunda e valiosa (Souza \& Soares, 2019).

Segundo Taille (2019) O desenvolvimento da inteligência permite que a motivação passa a ser despertada por um número cada vez maior de objetivos ou situações, estando a afetividade atrelada a esse desenvolvimento. As questões afetivas sempre pareceram ligadas à educação, e esse fato tem sua veracidade, pois ao longo da história nota-se que o papel do educador durante muito tempo foi direcionado à mulher, isto porque se acreditava que ela estava mais voltada às questões da afetividade, porém na atualidade professores, pais e educadores começam a perceber o quanto é importante os laços afetivos no processo de educação por parte de todos.

Segundo Veras e Ferreira (2010) se não há afeto prazeroso ou se ele não é percebido assim pela criança, esta poderá criar sentimentos de desconfiança em relação às suas possibilidades de sobrevivência e da interação com os demais. Poderá também desenvolver um sentimento generalizado de não ser aceita. De não contar com ninguém além de si própria, e muitas vezes buscar no isolamento e na solidão uma saída para sua vida. A afetividade tem um papel importante em nossa vida, somos afetivos por natureza e, com isso, damos respostas afetivas a todos os momentos de nossa vida.

A afetividade e a aprendizagem estão relacionadas com o contexto social e cultural em que se encontra o indivíduo. O desenvolvimento está intimamente relacionado ao contexto sociocultural em que a pessoa se insere e se processa da forma dinâmica (e dialética) através de rupturas e desequilíbrios provocadores de contínuas reorganizações por parte do indivíduo, a forma dinâmica do interagindo com o outro que a aprendizagem e o desenvolvimento acontecem e os bons sentimentos contribuem para que o indivíduo se desenvolva com mais segurança e predisposição para apreender novos conhecimentos (Rego, 2013).

Uma das características mais fortes da instituição familiar é a presença decisiva da afetividade permeando as relações. A afetividade decididamente é um aspecto muito importante e deve ser cultivado. Assim como na família, torna-se essencial para o processo de desenvolvimento e aprendizagem no ambiente escolar, pois não basta apenas ensinar, é necessário ter-se uma relação harmoniosa entre alunos e professores, e esse afeto constituirá progressivamente um referencial para a formação do caráter da criança, bem como para construção do respeito e a compreensão entre ambos, tendo como resultado a construção de conhecimento e aprendizagem (Sousa, Santos, \& Valverde, 2016).

Durante décadas transmitir educação equivalia a ensinar-se, trazendo explicação para o contexto acontecia da seguinte forma: o aluno recebia informação e o professor era o transmissor, não se preocupava com a necessidade individual do aluno, entretanto hoje o aluno é visto em sua individualidade, reconhecido a partir de sua socialização primária, familiar, pode 
desenvolver melhor sua autonomia. Isso significa maior autoestima, maior crença em suas convicções, mais forças para lutar pelo que deseja junto a pessoas e grupos com os quais mantém vínculos afetivos e ideias comuns (Ribeiro, 2010).

De acordo com Veras e Ferreira (2010) à medida que os alunos são tratados com carinho e afeto, tendem a ter mais liberdade e confiança com os educadores e se dispõem com mais alegria para aprender. Por outro lado, quando se ensina com mais rigidez e se tem a ausência da afetividade, os alunos reagem negativamente.

A afetividade no âmbito escolar proporciona resultados positivos no que se refere ao ensino e aprendizagem, desde que o professor tenha o compromisso e a responsabilidade com a educação, onde não se importe apenas em transmitir conhecimento, mas também escute seus alunos, promovendo uma troca de diálogos. Quando existe uma relação tendo como base o afeto, respeito mútuo, diálogo e confiança, tornam-se bases de crescimento, fontes de realização para aluno e professor (Bock, Furtado \& Teixeira, 2009).

\section{A afetividade no contexto familiar}

A família é peça chave no desenvolvimento pessoal da criança, mas a mesma tem que entender como abordar a criança, e como ajudar nos conflitos que poderão surgir em sua vida educacional e social, deste modo o aprendizado começa na relação família-criança. A afetividade começa na vida familiar do indivíduo, a criança nota quando seu responsável demonstra interesse e ajuda nas tarefas escolares e nas situações que o rodeiam no contexto escolar. A afetividade familiar é de suma importância na vida de qualquer sujeito, mas a mesma não deve interferir na afetividade escolar, as duas trabalham juntas, mas em contextos diferentes (Murgo, Alves, \& Francisco, 2016).

A afetividade familiar se diverge da afetividade escolar, mas ambas devem complementar uma a outra para garantir que a criança possa alcançar seus objetivos, afetividades que ocorre em cada contexto é fundamental para a criança assimilar conhecimentos teóricos e práticos. Assim tanto família e a escola atuando em conjunto em um meio afetivo concretiza o molde do caráter do indivíduo (Piaget, 1985).

Conforme Casarin e Ramos (2007) a presença da família desempenha um papel fundamental no desenvolvimento da criança, sendo sua primeira referência social, entretanto é na escola que a criança terá suas primeiras referências do mundo externo, imprescindível para a sua inserção na sociedade. Porém a ausência da família nesse processo pode influenciam negativamente no desempenho do aluno no ambiente escolar, e em outros aspectos sociais e de convivência.

Dentre uma das estratégias utilizadas para reafirmar a importância a afetividade familiar no contexto escolar e é por meio das reuniões pautadas entre pais e professores, no que acontece na escola e com o aluno, promover atividades de integração entre pais e filhos. Porém a ausência dos pais e/ ou familiares nesses eventos ainda representa uma problemática, pois o não envolvimento com a vida escolar da criança ou priorizar trabalho ou outras questões, podem refletir de forma negativa na afetividade da criança no ambiente escolar e familiar (Murgo et al., 2016).

Por isso é necessário que a família entenda a importância de escutar e debater sobre o ambiente escolar com seus filhos e as experiências do mesmo quanto indivíduo inserido nesse meio, pois existe uma influência fundamental dos pais na construção da autoestima e de comportamento na criança, e esse processo ocorre durante toda a formação do indivíduo, a nível social, comportamental, emocional (Casarin \& Ramos, 2007).

Para Murgo et al. (2016) proporcionar liberdade à criança para brincar, contar o que sente, respeitar sua opinião e valorizar suas atitudes e realizações positivas, ajudarão a formar uma mente confiante, pois a família é a figura mais importantes na vida da criança, desta forma o afeto e o reconhecimento das suas qualidades positivas pelos pais, possibilita um ambiente acolhedor e com potencial para o desenvolvimento da habilidade da criança, preparando a mesma para outros ambientes fora do contexto familiar. 
Através da afetividade é possível ensinar a crianças sobre os valores e comportamento, fazendo com que ela compreenda que tais ensinamentos fazem parte do meio e da cultura que está inserida. Com isso crescerá um adulto dotado de afeto, socialmente ativo e educadamente de bom caráter. Sendo que esses processos devem ocorrer na infância, sendo de difícil correção e mudança na fase adulta (Ariés, 1981).

\section{O papel do docente e a afetividade na escola}

No processo de ensino, o docente tem papel fundamental e precisa estar preparado e comprometido com sua ação educativa, pois assim exercerá sua função com responsabilidade, transmitindo os conhecimentos com prazer. Cabe ao professor o papel de mediador, aquele que ensina considerando, em particular, cada aluno, dentro de suas potencialidades (Ribeiro, 2010).

É através do ensino que o conhecimento de técnicas, valores e costumes são repassados, e para a criança a escola e todos os conhecimentos que a agregam é como se fossem um "novo mundo", que ao primeiro contato pode transparecer o medo do desconhecido do convívio com pessoas, de novas informações e ações diferentes, e nessa situação o modo como o professor se apresentar e estabelecer uma relação de afeto, pode promover uma sensação de bem estar e acolhimento, reduzindo as incertezas e inseguranças dos alunos (Fontana \& Cruz, 1997).

É comum que durante os primeiros anos da vida escolar tenham certos conflitos, pois a criança ainda está em seu processo de adaptação ao meio, e muitas vezes diante dessas situações o professor esteja despreparado, podendo agir de maneira relutante e até mesmo incompreensiva, na busca de soluções para os conflitos gerados por diversos estímulos emocionais, fazendo com que ocorro uma atenuação e fragilização da relação entre professor e aluno (Veras \& Ferreira, 2010).

Os professores também passam por situações e estímulos estressoras que podem afetar no seu desempenho em sala de aula de forma positiva ou negativa. O modo pelo qual são resolvidos e gerenciados esses conflitos refletem na relação entre o docente e o discente. Desta forma é necessário um olhar mais humanizado para interpretar e compreender ambos os lados, tornando a sala de aula e o ensino um ambiente favorável e agradável para o aprendizado (Tiba, 2015).

É necessário compreender cada criança individualmente para interpretar e trabalhar suas emoções e necessidades, porém devido à falta de capacitação e preparo prático, isso muitas vezes representa um para o profissional um desafio no ambiente escolar e que dificulta na resolução e intermediação de conflitos (Saltini,1997).

De acordo com Almeida e Mahoney (2007) a afetividade e a inteligência são inseparáveis no processo de crescimento e desenvolvimento da personalidade do indivíduo, e a escola como um local para experiências novas e construção de valores e hábitos é essencial para o afloramento e compreensão da afetividade pela criança, e assim tanto o ambiente como o professor influenciam nesse desenvolvimento, portanto é necessário que o mesmo busque estratégias e conheça como analisar e mediar as emoções dentro da sala de aula, fazendo com que tais situações tornem-se algo positivo para o crescimento e desenvolvimento pessoal de ambos.

Nos estudos de Freire (2019) destaca que a afetividade não é um componente durante a formação do docente, mas o ato de ensinar exige seriedade, compromisso, preparo emocional, físico e afetivo, tais requisitos não são abordados na formação inicial ou continuada. A afetividade entre professor e aluno não deve ser confundida com a relação de parentesco, pois a função do docente e mediar a criança no caminho do conhecimento e da vida na sociedade, sabendo lidar com as críticas e desafios que podem surgir nesse processo. É importante frisar que o professor e o ensino vão muito além da parte intelectual, mas também inclui o emocional, e ambas precisam ser discutidas e expostas, pois no processo de aprendizagem ambas se complementam.

O professor exerce um papel de extrema relevância no desenvolvimento das habilidades de seus alunos, mas também é necessário que ele crie um ambiente favorável para a aprendizagem, fazendo com que que o intelectual cresça em conjunto 
com o mundo emocional, assim o aluno poderá aprender a controlar suas emoções e se sentir motivado a prender (Sousa et al., 2016). Assim os professores podem ser considerados mestres, pois utilizam em suas aulas não só orientações oriundas da razão, mas também aliadas a emoção, estabelecendo assim um contexto apropriado para o desenvolvimento da inteligência e da afetividade de seus alunos (Freitas, 2000).

Portanto o professor que demonstre satisfação pelo ato de ensinar e pelo fato de estar na companhia de seus alunos e que instigue e respeite as opiniões dos discentes, que muitas vezes são divergentes das suas, e que busque em suas metodologias ensinar mais do que o que está no conteúdo, conquista a confiança dos seus discentes e que os ajudam a criar neles um vínculo de alguém aberto a conversas. Para a afetividade no que diz respeito à relação docente e discente isto é o suficiente (Almeida \& Mahoney, 2007; Freire, 2019).

\section{A importância da afetividade na educação infantil no ensino das crianças}

A infância é uma fase de intensa descoberta e criação de caráter, também do desenvolvimento de habilidades como a coordenação motora, a leitura e escrita, na qual a equipe pedagógica deve trazer o lúdico para facilitar o ensinamento destas, além disso estratégias e ações da afetividade também devem ser postas em prática a fim de melhorar o ensino e a qualidade de vida destas crianças (Arantes, 2003).

Deste modo a afetividade é necessária para a formação de pessoas felizes, seguras e capazes de conviver com o mundo que a cerca, pois ela é uma importante aliada nas metodologias pedagógicas, sendo responsável por criar vínculos relevantes e imprescindíveis para o ensino de educação infantil que deverá ser oferecido. Tendo como principal foco estabelecer bases para a personalidade humana, para a inteligência, para vida emocional e social da criança (Souza \& Soares, 2019).

No que se refere à afetividade na educação infantil, esta vem proporcionar estratégias a fim de melhorar a qualidade de vida no âmbito educacional e familiar. A educação Infantil é uma área que exige o máximo de atenção e certa preocupação por parte das instituições educacionais, já que em Constituição ir à escola é um direito a receber atendimento desde educacional a atendimento de saúde, pois quando a criança nasce, precisa de alguém que cuide dela e a ensine, pois ela é um ser que merece atenção, carinho, respeito, afeto e muito amor, para que consiga desenvolver seus traços de personalidade de forma integral, como um ser social do bem (Arantes, 2003).

Nesta perspectiva esta modalidade deve ser considerada como parte integrante da educação básica pública, já que a mesma é responsável, por ofertar os primeiros caminhos de formação e socialização da criança fora do círculo familiar, onde ela se torna um pilar da aprendizagem, que será juntamente com a família, responsável por ofertar as condições básicas e necessárias para que a criança se sinta segura e protegida (Souza \& Soares, 2019).

Lisboa (2003) descreve que as creches e escolas são de grande importância para o desenvolvimento cognitivo e emocional das crianças, pois nesses locais elas aprendem a brincar com as outras, respeitar limites, controlar a agressividade, relacionar-se com o adulto e aprender sobre si mesma e seus amigos, tarefa estas de natureza emocional fundamental para as crianças menores de seis anos para que estas se sintam importantes, livres e queridas.

\section{Considerações Finais}

O estudo proporcionou reflexões sobre o papel da afetividade no desenvolvimento educacional da criança inserida na educação infantil. Na qual pode se observar a afetividade e a sua importância tanto nos âmbitos educacional e familiar, e como as relações afetivas podem auxiliar no processo de ensinar e educar, de forma satisfatória. 
O trabalho conseguiu atender aos objetivos propostos, destacando a afetividade como uma abordagem prática no ensino das crianças como estratégia positiva no processo de aprendizagem, estratégias estas que podem ser desenvolvidas pelo professor no ambiente escolar, e também no âmbito familiar, pois o vínculo entre o aluno e sua família propiciam benefícios quanto a sociabilidade e aprendizagem.

A afetividade pode ser utilizada como uma ferramenta de auxílio ao professor, e se faz necessário que essa temática tenha maior visibilidade no campo do saber como uma estratégia complementar ao ensino. Contudo, a afetividade na educação infantil não é somente auxiliar o professor no processo de alfabetização do aluno, mas também proporcionar um olhar dinâmico e acolhedor tanto na socialização como no ensino como um todo, tornando o saber mais atrativo.

Almeja-se que o estudo proporcione e estimule os profissionais atuantes da educação para compreender o contexto laboral da afetividade no qual estão inseridos, e como relacionar a prática da afetividade nas vivências dos alunos, e da importância da mesma para o aprendizado e fortalecimento das relações sociais no contexto escolar. Mais estudos devem ser realizados a fim de investigar a relação da afetividade e o grau de aprendizado.

\section{Referências}

Almeida, L. R., \& Mahoney, A. A. (2007). Afetividade e aprendizagem: Contribuições de Henri Wallon (4a ed.) Editora Loyola.

Arantes, V. A. (Org.). (2003). Afetividade na escola: alternativas teóricas e práticas. Editora Summus.

Ariés, P. (1987). História Social da Criança e da Família (2a. ed). Zahar.

Bock, A. M. B., Furtado, O., \& Teixeira, M. L. T. (2009). Psicologias: uma Introdução ao Estudo de Psicologia (14a ed.). Saraiva.

Carvalho, L. O. R., Duarte, F. R., Menezes, A. H. N., \& Souza, T. E. S. (2019). Metodologia científica: teoria e aplicação na educação a distância. Petrolina: Fundação Universidade Federal do Vale do São Francisco.

Casarin, N. E. F., \& Ramos, M. B. J. (2007). Família e aprendizagem escolar. Rev. Psicopedagogia, 24(74), $182-201$.

Fontana, R. A. C., \& Cruz, M. N. (1997). Psicologia e trabalho pedagógico. Atual.

Freire, P. (2019). Educação como prática da liberdade. Paz e Terra.

Freitas, K. S. (2000). Uma Inter-relação: políticas públicas, gestão democrático-participativa na escola pública e formação da equipe escolar. Em Aberto, 17 (72), 47-59.

Lakatos, E. M., \& Marconi, M. A. (2010). Fundamentos de metodologia científica (7a ed). Atlas.

Leite, S. A. S. (2012). Afetividade nas práticas pedagógicas. Temas em Psicologia, 20 (2), 355 - 368. 2012.

Lisboa, A. M. J. (2003). O seu filho no dia-a-dia: dicas de um pediatra experiente (2a. ed.) Record.

Mendes, K. D. S., Silveira, R. C. C. P., \& Galvão, C. M. (2008). Revisão integrativa: método de pesquisa para a incorporação de evidências na saúde e na enfermagem. Texto Contexto Enferm, 17(4), 758-64.

Murgo, C. M., Alves, W. A., \& Francisco, M. V. (2016). A afetividade na relação professor-aluno: perspectivas de estudantes de Pedagogia. Rev. educ, 21(2), 211-220.

Ornellas M. L. S. (2009). Educação, afeto e representação social. In: Nascimento, A. D., Hetkowski, T. M (Orgs.), Educação e contemporaneidade: pesquisas científicas e tecnológicas (pp. 277-293). EDUFBA.

Piaget, J. (1985). A construção do real na criança. Zahar.

Rego, M. C. (2013). Vygotsky: Uma perspectiva histórico-cultural da educação. Vozes.

Ribeiro, M. L. (2010). A afetividade na relação educativa. Estudos de Psicologia, 27(3), 403-412.

Saltini, C. J. P. (1997). Afetividade e inteligência. Wak.

Sousa, P. B., Santos, F. C., \& Valverde, C. (2016). A influência da afetividade no processo de aprendizagem. Pedagog. Foco, 11 (6), $168-179$.

Souza, T. L. L., \& Soares, H. C. C. (2019). A afetividade na educação infantil. Revista Científica Online, 11 (1), 01-13.

Taille, Y. L (2019). Piaget, Vygotsky, Wallon: teorias psicogenéticas em discussão. Summus. 
Research, Society and Development, v. 10, n. 4, e36410414053, 2021

(CC BY 4.0) | ISSN 2525-3409 | DOI: http://dx.doi.org/10.33448/rsd-v10i4.14053

Tiba, I. (2015). Quem Ama, Educa! Formando Cidadãos Éticos. Integrare.

Veras, R. S., \& Ferreira, S. P. A. (2010). A afetividade na relação professor-aluno e suas implicações na aprendizagem, em contexto universitário. Educar em Revista, (38), 219-235. 